\title{
PROGNOSTIC VALUE OF SHOCK INDEX IN CHILDREN WITH SEPSIS/SEPTIC SHOCK
}

\author{
Aiswarya Rajendran'1, Brinda Sivalingam², Rajasekar Srinivasan ${ }^{3}$
}

1 Junior Resident, Thanjavur Medical College, Thanjavur, Tamilnadu, India.

${ }^{2}$ Assistant Professor, Department of Paediatrics, Thanjavur Medical College, Thanjavur, Tamilnadu, India.

3Professor and HOD, Department of Paediatrics, Thanjavur Medical College, Thanjavur, Tamilnadu, India.

\section{BACKGROUND}

ABSTRACT

Sepsis in paediatric age group is likely due to result of sequence of disorders that is due to infection by viruses, bacteria, parasite, fungi or toxins of organisms. The outcome is improved with early recognition and resuscitation of sepsis and septic shock in the golden first few hours of PICU admission. Infection is defined as a suspected or proven (by positive culture, tissue stain or polymerase chain reaction test) infection caused by any pathogen or a clinical syndrome associated with a high probability of infection.

Aims and Objectives- To find the association between PICU shock index and mortality in children with sepsis/ septic shock and to explore the cut-off values for shock index and to determine the change in shock index during the first 6 hours of PICU stay and its outcome.

\section{MATERIALS AND METHODS}

Study Design: Observational cohort study.

Study Place: Paediatric Intensive Care Unit, Rajamirasudhar Hospital attached to Thanjavur Medical College.

Study Period: 6 months period from Jan to June 2017. 50 children who presented with sepsis/ septic shock were included in the study. Children were classified as per their age as $<1$ year, $>1$ year $-<6$ years and $>6$ years. They were also grouped as sepsis, severe sepsis and septic shock as per the International Sepsis Consensus Conference definition of sepsis in 2005. Clinical parameters like heart rate and systolic blood pressure was recorded, following which shock index was calculated over $0,1,2,4$ and 6 hours of PICU admission and trend was noticed. Patients were finally divided into 2 groups as per outcome, i.e. survival/ death.

\section{RESULTS}

Data analysis was done using GraphPad Prism 5. Cut-off values of shock index were analysed using Receiver Operator Curve and their relative risk of mortality was studied. Higher values of shock index and increasing trend of shock index was associated with increased mortality.

\section{CONCLUSION}

SI can be a promising marker for risk of mortality in children with sepsis/ septic shock. It is simple, non-invasive and bedside clinical tool to identify high-risk children and help us keep vigilant. The obtained cut-off values indicate that higher the SI, higher is the risk of mortality.

\section{KEY WORDS}

Mortality Risk, Prognostic Value, Shock Index, Sepsis and Septic Shock.

HOW TO CITE THIS ARTICLE: Rajendran A, Sivalingam B, Srinivasan R. Prognostic value of shock index in children with sepsis/septic shock. J. Evolution Med. Dent. Sci. 2018;7(23):2737-2741, DOI: 10.14260/jemds/2018/618

\section{BACKGROUND}

Sepsis in paediatric age group is likely due to result of sequence of disorders that is due to infection by viruses, bacteria, parasite, fungi or toxins of organisms. The outcome is improved with early recognition and resuscitation of sepsis and septic shock in the golden first few hours of PICU admission. Infection is defined as a suspected or proven (By positive culture, tissue stain or polymerase chain reaction test) infection caused by any pathogen or a clinical syndrome associated with a high probability of infection.[1]

'Financial or Other Competing Interest': None.

Submission 19-04-2018, Peer Review 19-05-2018,

Acceptance 25-05-2018, Published 04-06-2018.

Corresponding Author:

Dr. Brinda Sivalingam,

Plot No. 17, Arokiyasamy Nagar,

Kumbakonam-612001,

Tamilnadu, India.

E-mail: drbrindasiva@gmail.com

DOI: $10.14260 /$ jemds $/ 2018 / 618$
Systemic Inflammatory Response Syndrome [SIRS] is a cascade of events initiated as a result of inflammation due to exaggerated host response to the triggering agent, infection or non-infectious agent. Tachypnoea and tachycardia with hyperthermia or hypothermia is the triad of SIRS. If SIRS is recognised and intervened early, the inflammatory cascade is disrupted. But sometimes the exaggerated host immune response causes continuous damage resulting in increased cardiac output, increased tissue oxygen demand and peripheral vasodilatation, the so called warm shock. If SIRS is not recognised early, there may be fall in cardiac output, increase in peripheral resistance and blood gets shunted resulting in cold shock. It causes hypoxia, metabolic acidosis, MODS- Multiple Organ Dysfunction Syndrome and Death. The MODS and the associated complications is the cause of death rather than the acute hypotensive phase.

SIRS plus a suspected or proven infection is defined as sepsis. Sepsis in the presence of evidence for organ dysfunction is defined as severe sepsis. Sepsis plus cardiovascular organ dysfunction is defined as septic shock. Shock ${ }^{[2]}$ is defined by the inability of the body to meet the 
metabolic demands by delivering adequate oxygen to vital organs and tissues. Presence of altered organ function such that homeostasis cannot be maintained without medical intervention is defined as MODS. Release of TNF, interferon, IL $1,2,6,8,12$ and platelet activating factor[3] has a central role in the pathogenesis of sepsis. Initial management of shock includes volume replacement with isotonic saline, correction of hypoglycaemia and hypocalcaemia and initiation of inotropic support and further aggressive management with catecholamines and so on.

There are various scores to predict the mortality and severity of illness when admitted in PICU.[4-7] In this study, the range in normal heart rate per minute for age was considered as per[8] paediatric advance life support guidelines, 2015. Some of the common causes of tachycardia include increased body temperature, sympathetic stimulation of the heart and toxic conditions of the heart. Causes of sympathetic stimulation causing tachycardia includes blood loss resulting in shock causing sympathetic reflex stimulation of the heart and weakened myocardium causing pump failure causing sympathetic stimulation to increase the HR. Blood pressure is defined ${ }^{[9]}$ as the lateral pressure exerted by the column of blood on the walls of arteries. Normal blood pressure in children by age ${ }^{[10]}$ as per paediatric advance life support guidelines, 2015. Hypotension[11] in children is defined by the various thresholds of systolic blood pressure. For measuring BP, cuff sizes for various age groups were determined. ${ }^{[12]}$ With HR and SBP, Shock Index was calculated. SI= HR/ SBP.

Repeated studies in children and adults have demonstrated that early recognition and aggressive resuscitation of shock is associated with better outcome. By determining the Shock index, it has the advantage of distinguishing from suppressed sympathetic state, use of anticholinergic drugs, sedation, which all can be confounding factors while assessing critically ill children, as heart rate and blood pressure individually cannot differentiate the above states.[13]

Thus, we sought to use a simple, non-invasive, metric tool that can serve as a predictive marker of high-risk children with sepsis/ septic shock. Though normal range of shock index has been suggested earlier,[14] it is difficult to define the normal cut-off values for SI in children.

Thus, this study was done to investigate the association between PICU shock index and mortality in children with sepsis/ septic shock and to explore cut-off values for ICU mortality, how change in shock index over the first 6 hours of ICU admission is associated with outcome.

\section{MATERIALS AND METHODS}

\section{Study Design}

Observation cohort study.

\section{Place of Study}

Paediatric Intensive Care Unit of the Department of Paediatrics, Rajamirasudhar Hospital attached to Thanjavur Medical College.

Study Period- 6 months from January to June 2017.

Sample Size- 50.
Clearance was obtained from the Ethical Committee of the hospital for conducting the study. Children were categorised into sepsis, severe sepsis and septic shock. Children were also grouped according to age as $<1$ year, 1 to 6 years and $>6$ years. At admission, children were grouped into respective categories according to International Pediatric Sepsis Consensus Conference definition of sepsis.

\section{Inclusion Criteria}

Children (1 month to 12 years) admitted in PICU, Thanjavur Medical College, referred/diagnosed as sepsis/septic shock defined as per International Pediatric Sepsis Consensus Conference, 2005.

\section{Exclusion Criteria}

Children with hypovolaemic shock, cardiogenic shock, neurogenic shock, anaphylactic shock and obstructive shock were excluded from the study.

\section{Clinical Parameters}

Heart rate and systolic blood pressure.

\section{Methods and Methodology}

Children admitted in PICU, Rajamirasudhar Hospital attached to Thanjavur Medical College who satisfy the inclusion criteria were studied. Written consent was obtained from parents/ caregivers. HR, systolic BP and diastolic BP was recorded at 0, 1, 2, 4 and 6 hours. Heart rate was counted by auscultation and BP was measured using mercury sphygmomanometer using appropriate cuff sizes at various times. Patients were divided into 2 groups according to outcome (Death/ Survival).

\section{Data Definitions}

Shock Index was calculated as HR/ SBP. Mode of measurement of blood pressure was non-invasive. For unrecordable BP, a systolic BP of $30 \mathrm{mmHg}$ was considered (as per PIM score). HR of 0 was used for unrecordable BP. Hence, during a cardiac arrest, SI was 0 . Values of 0 were not included for multivariate analysis or trend. An improvement in shock index was defined as decrease in SI at 0 hours and 6 hours. And the trend of shock index (Increasing/Decreasing/Static) during the first 6 hours was also noted. Death was categorised as early death (Within 24 hours of admission/ Referral) or late death (after 24 hours).

Different age adjusted and hourly cut-off values, their distribution, sensitivity, specificity as prognostic marker of sepsis/ septic shock, confidence interval, likelihood ratio and the area under ROC (Receiver-Operating Curve) was calculated for absolute values of shock index and changes in shock index at admission and hourly intervals and the relative risk of mortality obtained.

\section{Statistical Analysis}

Data analysis was done by GraphPad Prism 5. Data were expressed as mean \pm SD, percentage for appropriate parameters. Groups were compared in aspects of increase or decrease in shock index using relative risk and expressed with 95\% confidence interval. Receiver operator curve was constructed with sensitivity against 1 - specificity for shock index at 0 hours and 6 hours for children $<1$ years, $>1$ year to $<6$ years, $>6$ years to $<12$ years. 


\section{RESULTS}

The total number of subjects studied were 50. Average age group of the study population was $4.4 \pm 3.4$ years. Average sex ratio was 1: 1 . They were classified as per severity of illness as $40 \%$ with sepsis $(n=20), 30 \%$ with severe sepsis $(n=15)$ and $30 \%$ with septic shock $(n=15)$.

\begin{tabular}{|c|c|c|c|}
\hline Sl. No. & Age in Years & Outcome & Mortality \\
\hline 1 & \multirow{2}{*}{ All age $(\mathrm{n}=50)$} & Survived $(\mathrm{n}=34)$ & \multirow{2}{*}{$32 \%$} \\
\cline { 3 - 3 } & & Died $(\mathrm{n}=16)$ & \\
\hline 2 & $\leq 1$ year $(\mathrm{n}=15)$ & Survived $(\mathrm{n}=8)$ & \multirow{2}{*}{$46.67 \%$} \\
\cline { 3 - 3 } & Died $(\mathrm{n}=7)$ & \\
\hline 3 & $>1$ to $\leq 6$ years $(\mathrm{n}=19)$ & Survived $(\mathrm{n}=5)$ & $87.5 \%$ \\
\hline
\end{tabular}

\begin{tabular}{|c|c|c|c|}
\hline & & Died $(n=14)$ & \\
\hline \multirow{3}{*}{4} & \multirow{3}{*}{$>6$ to $\leq 12$ years $(n=16)$} & Survived $(\mathrm{n}=14)$ & \multirow{3}{*}{$12.5 \%$} \\
\hline & & & \\
\hline & & Died $(n=2)$ & \\
\hline
\end{tabular}

Table 1. Distribution of Mortality in various Age Groups

In the age group $<1$ year, the distribution of severity was severe sepsis $>$ sepsis shock $>$ sepsis.

In the age group $>1$ to $<6$ years, the distribution of severity was septic shock $>$ sepsis $>$ severe sepsis.

In the age group $>6$ years to 12 years, the distribution of severity was sepsis $>$ severe sepsis= septic shock.

\begin{tabular}{|c|c|c|c|c|c|c|c|c|c|c|c|c|}
\hline \multirow[b]{2}{*}{$\begin{array}{c}\text { Sl. } \\
\text { No. }\end{array}$} & \multirow{2}{*}{\multicolumn{2}{|c|}{ Age in Years }} & \multicolumn{2}{|c|}{ SI (0 hr) } & \multicolumn{2}{|c|}{ SI (1 hr) } & \multicolumn{2}{|c|}{ SI (2 hrs) } & \multicolumn{2}{|c|}{ SI (4 hrs) } & \multicolumn{2}{|c|}{ SI (6 hrs) } \\
\hline & & & $\stackrel{\infty}{\Xi}$ & 苛 & $\stackrel{\mathscr{E}}{\vdots}$ & 뮬. & $\stackrel{n}{E}$ & 뮬. & 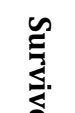 & 뮬. & $\stackrel{n}{E}$ & 묭 \\
\hline \multirow{2}{*}{1} & \multirow{2}{*}{$\begin{array}{c}\text { All age } \\
\text { ( } \mathrm{n}=34 \text { in survived } \\
\text { and } 16 \text { in died) }\end{array}$} & Mean & 1.61 & 2.1 & 1.52 & 2.02 & 1.43 & 1.8 & 1.44 & 1.74 & 1.39 & 1.8 \\
\hline & & SD & 0.49 & 0.94 & 0.5 & 0.92 & 0.41 & 0.7 & 0.45 & 0.63 & 0.38 & 0.75 \\
\hline \multirow{2}{*}{2} & \multirow{2}{*}{$\begin{array}{c}\leq 1 \text { year } \\
\text { ( } \mathrm{n}=8 \text { in survived } \\
\text { and } 7 \text { in died) }\end{array}$} & Mean & 2.04 & 2.43 & 1.87 & 2.29 & 1.78 & 1.72 & 1.88 & 1.83 & 1.77 & 1.88 \\
\hline & & SD & 0.59 & 1.01 & 0.66 & 0.98 & 0.51 & 0.42 & 0.49 & 0.51 & 0.41 & 0.53 \\
\hline \multirow{2}{*}{3} & \multirow{2}{*}{$\begin{array}{c}>1 \text { to } \leq 6 \text { years } \\
(\mathrm{n}=12 \text { in survived } \\
\text { and } 7 \text { in died })\end{array}$} & Mean & 1.63 & 1.87 & 1.46 & 1.82 & 1.43 & 1.87 & 1.42 & 1.78 & 1.35 & 1.85 \\
\hline & & SD & 0.3 & 0.81 & 0.29 & 0.86 & 0.28 & 0.84 & 0.36 & 0.78 & 0.3 & 0.99 \\
\hline \multirow[b]{2}{*}{4} & \multirow{2}{*}{$\begin{array}{c}>6 \text { to } \leq 12 \text { years } \\
\text { (n=14 in survived } \\
\text { and } 2 \text { in died) }\end{array}$} & Mean & 1.35 & 1.76 & 1.38 & 1.79 & 1.23 & 1.83 & 1.2 & 1.33 & 1.21 & 1.33 \\
\hline & & SD & 0.39 & 1.36 & 0.48 & 1.32 & 0.31 & 1.41 & 0.31 & 0.61 & 0.29 & 0.46 \\
\hline
\end{tabular}

Table 2. Average Shock Index at 0, 1, 2, 4 and 6 hours Stratified by Age and Outcome

Data are expressed as mean \pm SD, except mortality and outcome which are expressed as percentage and absolute number respectively.

\begin{tabular}{|c|c|c|c|c|}
\hline मं z & 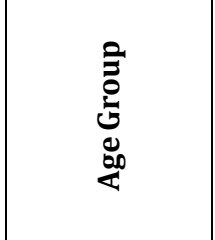 & 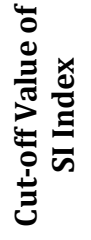 & 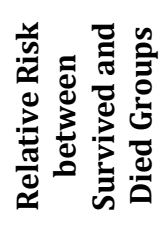 & 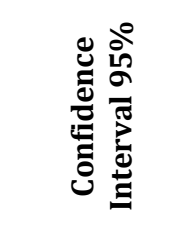 \\
\hline \multirow{3}{*}{1} & \multicolumn{4}{|c|}{$\leq 1$ year $(n=15)$} \\
\hline & SI index at $0 \mathrm{hr}$ & 2.16 & 2.01 & 0.67 to 5.91 \\
\hline & SI index at $6 \mathrm{hr}$ & 1.77 & 2.85 & 0.78 to 10.37 \\
\hline \multirow{3}{*}{2} & \multicolumn{4}{|c|}{$>1$ to $\leq 6$ years } \\
\hline & SI index at $0 \mathrm{hr}$ & 1.43 & 2.14 & 0.71 to 6.4 \\
\hline & SI index at $6 \mathrm{hr}$ & 1.16 & 4.41 & 0.75 to 25.7 \\
\hline \multirow{3}{*}{3} & \multicolumn{4}{|c|}{$>6$ to 12 years } \\
\hline & SI index at $0 \mathrm{hr}$ & 2.03 & 7 & 0.67 to 72 \\
\hline & SI index at $6 \mathrm{hr}$ & 1.56 & 15 & 2.25 to 99.7 \\
\hline \multicolumn{5}{|c|}{$\begin{array}{l}\text { Table 3. Relationship between the SI at various Time in } \\
\text { various Age Groups with Outcome in the Study }\end{array}$} \\
\hline
\end{tabular}

For $\leq 1$ year at 0 hours of admission, if the SI is $>2.16$ then there is 2.01 times relative risk of mortality when compared with other values with a confidence interval of 0.67 to 5.91 .

For $\leq 1$ year, at 6 hours, if the SI is $>1.77$ then there is 2.85 times relative risk of mortality when compared with other values with a confidence interval of 0.78 to 10.37 .
For $>1$ to $<6$ years, at 0 hour, SI value of $>1.43$ has 2.14 times relative risk of mortality when compared with other values with a confidence interval of 0.71 to 6.4 .

For $>1$ to $<6$ years, at 6 hours, SI value of $>1.16$ has increased risk with a relative risk of 4.41 with a confidence interval of 0.75 to 25.7 .

For $>6$ to 12 years, at 0 hours, if the SI value $>2.03$, there is 7 times relative risk with a confidence interval of 0.67 to 72.

For $>6$ to 12 years, at 6 hours, if the SI value $>1.53$, there is 15 times relative risk of mortality with a confidence interval of 2.25 to 99.7 .

\begin{tabular}{|c|c|c|c|c|}
\hline $\begin{array}{l}\text { Sl. } \\
\text { No. }\end{array}$ & $\begin{array}{c}\text { Trend with } \\
\text { Outcome }\end{array}$ & $\begin{array}{c}\text { Number with } \\
\text { Proportion N } \\
\text { (\%) }\end{array}$ & $\begin{array}{c}\text { Relative } \\
\text { Risk }\end{array}$ & $\begin{array}{c}95 \% \\
\text { Confidence } \\
\text { Interval }\end{array}$ \\
\hline \multirow{3}{*}{1} & \multicolumn{2}{|c|}{$\begin{array}{c}\text { Increase in SI from } 0 \text { hour to } \\
6^{\text {th }} \text { hour }(n=16)\end{array}$} & \multirow{6}{*}{1.56} & \multirow{6}{*}{0.7 to 3.49} \\
\hline & Survived & $9(56.25)$ & & \\
\hline & Died & $7(43.75)$ & & \\
\hline \multirow{3}{*}{2} & \multicolumn{2}{|c|}{$\begin{array}{c}\text { Decrease in SI from } 0 \text { hour to } \\
6^{\text {th }} \text { hour }(n=34)\end{array}$} & & \\
\hline & Survived & $23(76.6)$ & & \\
\hline & Died & $9(23.7)$ & & \\
\hline
\end{tabular}

Table 4. Relationship between the trend in Shock Index change from 0 to 6 hrs with Outcome in the Study Sample

In our study, of those who survived 9 (56\%) and among died 7 (43.75\%) had increase in SI and decrease in shock index was noted in $23(76.6 \%)$ of survived and $9(23.7 \%)$ of died. 
Thus, we can infer that if there is an increase in SI between admission and 6 hours, then there is 1.56 times relative risk of mortality or if there is decrease in SI between admission and 6 hours then there is 1.56 times chances of survival.

\section{DISCUSSION}

This study demonstrates the hourly cut-off values of shock index from 0 hour till 6 hours of PICU admission in patients admitted with a diagnosis of sepsis/ septic shock. The normal range of shock index is taken as in the study by Yuki Yasaka et al as the standard.

Cut-Off Value for Shock Index at $\mathbf{0}$ and $\mathbf{6}$ Hours in $\leq 1$ Year The normal range quoted by Yuki Yasaka et al for the age group $<1 \mathrm{yr}$ is 0.8 to 2.3 . The cut-off value obtained in our study at 0 hours was 2.16 and at 6 hours was 1.77 , that is if the SI in the age group $<1$ year at 0 hours is 2.16 there is 2.01 times relative risk of mortality with a confidence interval of 0.67 to 5.91 , sensitivity of $57.14 \%$ and specificity of $75 \%$. Similarly, at 6 hours in age group $\leq$ one year if the SI is $>1.77$ there is 2.85 times relative risk of mortality with a $\mathrm{CI}$ of 0.78 to 10.37 , sensitivity of $71.43 \%$ and specificity of $75 \%$.

\section{Cut-Off Value for Shock Index at 0 and 6 hours in 1 to 6 Years:}

The normal range quoted by Yuki Yasaka et al for the age group 1 yr. to 6 yrs. is 0.7 to 1.22 , after taking mean of 2 age groups. The cut-off value obtained in our study at 0 hours was 1.43 and at 6 hours was 1.16, that is if the SI in the age group 1 to 6 years at 0 hours is 1.43 there is 2.14 times relative risk of mortality with a confidence interval of 0.71 to 6.4 , sensitivity of $84.71 \%$ and specificity of $60 \%$. Similarly, at 6 hours in age group of 1 to 6 years, if the SI is $>1.16$ there is increased risk of mortality with a relative risk of 4.41 with CI of 0.75 to 25.7 with sensitivity of $100 \%$ and specificity of $80 \%$.

\section{Cut-Off Value for Shock Index at 0 and 6 Hours in $>6$ to 12 Years}

The normal range quoted by Yuki Yasaka et al for the age group > 6 yrs. to 12 yrs. is 0.5 to 1.2 , taking average mean of two age groups. However, in our study, the cut-off value obtained at 0 hours was 2.03 and at 6 hours was 1.56 . That is, if the SI in the age group $>6-12$ years at 0 hours is $>2.03$, there is 7 times relative risk of mortality with a confidence interval of 0.67 to 72 , sensitivity of $50 \%$ and specificity of $96.86 \%$. Similarly, at 6 hours in age group $>6-12$ years if the SI is $>1.56$ there is 15 times relative risk of mortality with a CI of 2.25 to 99.7 , sensitivity of $50 \%$ and specificity of $85.71 \%$.

In our study, age stratified cut-off value of SI at 0 and 6 hours is closely greater than the upper limit of standard normal range of SI given in the study by Yuki Yasaka for the age groups $\leq 1$ year and $>1$ year to $<6$ years, whereas for the age group $>6$ years to 12 years, the cut-off value obtained in our study was far greater compared to the upper limit of standard normal range of SI. The reason for this relatively higher cut-off value in the age group $>6$ to 12 years in our study may be because of better compensation to shock in older children and may be due to varied distribution of severity and outcome.

\section{Higher SI associated with Increased Risk of Mortality}

In the same study quoted above, it was obtained that higher SI was associated with mortality in children 1 to 3 years and 6 to 12 years and observed that higher values of SI was associated with increased risk of mortality in children with sepsis/ septic shock, but could not obtain clear cut-off values of SI for mortality in any age group.

In our study, two-way repeated measures ANOVA was done to test the significance for the difference between the SI at various time points with age category and no difference was found statistically. Also as the sample size was small, statistical association could not be obtained. However, clinically these differences hold values and it appears that the mean SI values of died groups are higher than the mean SI values of survived groups and thus correlates increased risk of mortality.

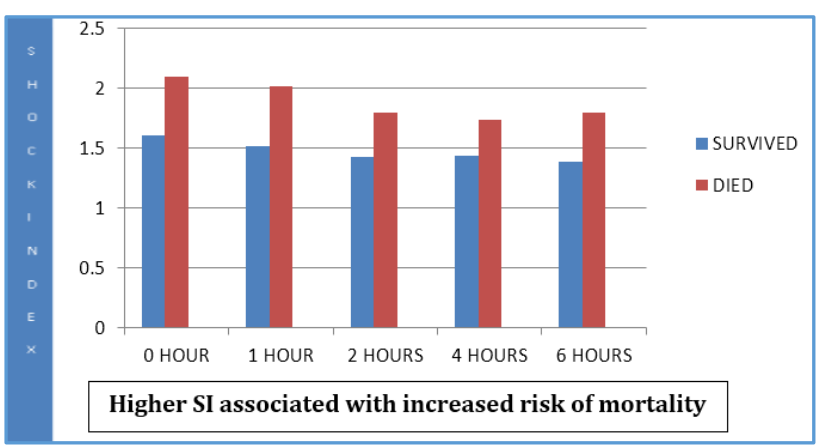

Figure 1. The Mean SI values of Died groups are Higher than the Mean SI values of Survived Groups and thus Correlates Increased Risk of Mortality

Trend of Shock Index from 0 to 6 Hours of Admission Studies done in adults have been able to show that persistent elevations in SI correlate with poor outcome. In Yuki Yasaka et al study, neither improvement in SI over 6 hours nor persistent elevation of SI was predictor of PICU mortality. However, on studying the children with a higher SI at admission, the fall in SI was associated with better outcome in the group 1 - 3 years and > 12 years. In our study, increase in trend of SI from 0 hours to 6 hours of admission was associated with 1.56 times relative risk of mortality with a confidence interval of 0.7 to 3.49 .

In the 1960s, Allgower and Buri[15] first introduced Shock index that is defined as HR to SBP. They observed that a normal value of SI ranges from 0.5 to 0.7 in a healthy adult.

Rousseaux, Jeremie et al[16] (2013) demonstrated that SI was clinically relevant and easily calculated predictor of mortality. Age adjusted SI were different between survivors and non-survivors at 0 and 6 hours and an abnormal SI both at admission and at 6 hours was predictor of death.

Yuki Yasaka et al (2013) tried to explore the cut-off values of shock index for ICU mortality and how change in shock index over the first 6 hours of ICU admission is associated with outcome. 


\section{CONCLUSION}

Shock Index can be a promising marker of risk of mortality in children with sepsis/ septic shock. SI is easily obtainable, simple, non-invasive, inexpensive, non time consuming, bedside clinical tool to identify the high-risk children that may help us keep vigilant. With the obtained cut-off values to determine the risk of mortality, it was identified that the risk of mortality increases for higher values of SI and with increasing trend in the shock index. Therefore, children with elevated SI may benefit from more aggressive resuscitation and intensive care.

\section{Abbreviations}

- HR- Heart Rate.

- MODS - Multiple Organ Dysfunction Syndrome.

- PIM Score- Paediatric Index of Mortality.

- $\quad$ SIRS- Systemic Inflammatory Response Syndrome.

- $\quad$ SBP- Systolic Blood Pressure.

- $\quad$ SI - Shock Index.

\section{REFERENCES}

[1] Goldstein B, Giroir B, Randolph A, et al. International pediatric sepsis consenses conference: definition for sepsis and organ dysfunction in paediatrics. Pediatric Crit Care Med 2005;6(1):2-8.

[2] David A, Turner, Cheifetz IM. Shock. Nelson textbook of paediatrics. Vol. 1. 20 $0^{\text {th }}$ edn. First South Asia edn. Elsevier Publishers 2016:516-28.

[3] Santhanam S. Pediartic sepsis: pathogenesis of sepsis. Medscape, Aug 2017.

[4] Costa GA, Delgado AF, Ferraro A, et al. Application of the pediatric risk of mortality score (prism) score and determination of mortality risk factors in a tertiary pediatric intensive care unit. Clinics (Sao Paulo) 2010;65(11):1087-92.

[5] Bhadoria P, Bhagwat AG. Severity scoring systems in paediatric intensive care units. Indian Journal of Anaesthesia 2008;52(Suppl 5):663-75.
[6] Haque A, Siddiqui NR, Munir O, et al. Association between vasoactive-inotropic score and mortality in pediatric septic shock. Indian Pediatr 2015;52(4):3113.

[7] Rady HI, Mohamed SA, Mohssen NA, et al. Application of different scoring systems and their value in pediatric intensive care unit. Egyptian Pediatric Association Gazette 2014;62(3-4):59-64.

[8] Leon C, Ricardo A, Samson, et al. Novak C and Gill P for PedsCases.com. Pediatric vital signs reference chart. Pediatric advance life support guidelines 2015. April 21, 2016.

[9] Pal GK, Pal P. Textbook of practical physiology. Chapter - 29. Orient Longman Private Limited., 2001, reprint 2003: p. 183-93.

[10] Fleegler E, Kleinman M. Pediatric Advance Life Support (PALS) guidelines, 2015.

[11] Novak C, Gill P. Pediatric vital signs reference chart. Pediatric advance life support, hypotention part 2 . 2009-2010

[12] Aruchamy, Lakshmanaswamy. Clinical pediatrics. Chapter -3 . $3^{\text {rd }}$ edn. Lippincott Williams and Wilkins 2010: p. 765.

[13] Ray S, Cvetcovic M, Brierley J, et al. Shock index values and trends in pediatric sepsis. Shock 2016;46(3):27986.

[14] Yasaka Y, Khemani RG, Markovitz BP. Is shock index associated with outcome in children with sepsis/septic shock? Pediatr Crit Care Med 2013;14(8):e372-e9.

[15] Allgower M, Buri C. Shock index. Dtsch Med Wochenschr 1967;46:1-10.

[16] Rousseaux J, Grandbastien B, Dorkenoo A, et al. Prognostic value of shock index in children with septic shock. Pediatr Emerg Care 2013;29(10):1055-9. 